\title{
Structure and Thermoelectric Properties of Te-Ag-Ge-Sb (TAGS) Materials Obtained by Reduction of Melted Oxide Substrates
}

\author{
B. KUSZ, ${ }^{1}$ T. MIRUSZEWSKI, ${ }^{1}$ B. BOCHENTYN, ${ }^{1,2}$ M. ŁAPIŃSKI, ${ }^{1}$ \\ and J. KARCZEWSKI ${ }^{1}$ \\ 1.-Faculty of Applied Physics and Mathematics, Gdansk University of Technology, ul. Naru- \\ towicza 11/12, 80-233 Gdańsk, Poland. 2.-e-mail: bbochentyn@mif.pg.gda.pl \\ $\mathrm{Ge}_{0.77} \mathrm{Ag}_{0.1} \mathrm{Sb}_{0.13} \mathrm{Te}_{1}$ alloy was fabricated by a novel two-step route. Firstly, \\ oxide reagents were melted at high temperature and quenched into pellets. \\ The pellets were milled to powder and then reduced in hydrogen at various \\ temperatures for various periods of time. Energy-dispersive x-ray analysis \\ indicated the possibility of successful fabrication of stoichiometric thermo- \\ electric materials from the Te-Ag-Ge-Sb system. The electrical conductivity \\ and Seebeck coefficient have been determined over the temperature range \\ from $20^{\circ} \mathrm{C}$ to $340^{\circ} \mathrm{C}$ in argon atmosphere. It was also shown that, for most of \\ the fabricated samples, the crystallite size as well as electrical parameters \\ such as the electrical conductivity, Seebeck coefficient, and figure of merit $(Z T)$ \\ increased with increasing reduction time. The highest value of $Z T(\sim 1.0$ at \\ $340^{\circ} \mathrm{C}$ ) was obtained for samples reduced in hydrogen atmosphere at $400^{\circ} \mathrm{C}$ for \\ $20 \mathrm{~h}$ and $40 \mathrm{~h}$.
}

Key words: Reduction in hydrogen, TAGS, alloy, thermoelectric, $Z T$

\section{INTRODUCTION}

In recent years, thermoelectric (TE) materials have been widely studied for use with alternative energy sources and in novel energy conversion applications. The thermoelectric performance of a material is quantified by a dimensionless parameter called the figure of merit $(Z T)$ :

$$
Z T=\frac{\sigma \alpha^{2} T}{\kappa},
$$

where $\alpha$ is the Seebeck coefficient, $\sigma$ is the electrical conductivity, and $\kappa$ is the thermal conductivity. It is clear from Eq. 1 that there are two ways to increase the value of $Z T$ and thereby improve the thermoelectric performance: One is enhancement of the electrical conductivity and Seebeck coefficient, while the second is decrease of the thermal conductivity. Slack defined that, theoretically, the best thermoelectric material would be a narrow-bandgap

(Received August 25, 2015; accepted November 11, 2015; published online December 28, 2015) semiconductor with high-mobility carriers. ${ }^{1}$ This kind of material should achieve a compromise between the mobility of charge carriers and the effective mass. These parameters influence the electrical conductivity and Seebeck coefficient, respectively. On the other hand, the thermal conductivity should be minimized for thermoelectric applications. The total thermal conductivity of a material is the sum of an electronic component related to transport of heat by electrons/holes $\left(\kappa_{\mathrm{e}}\right)$ and a lattice component $\left(\kappa_{1}\right)$ related to phonons traveling through the lattice. As the electronic thermal conductivity is related to the electrical conductivity by the Wiedemann-Franz relationship,

$$
\kappa_{\mathrm{e}}=L_{0} T \sigma,
$$

where $L_{0}$ denotes the Lorenz constant (reported equal to $2.0 \times 10^{-8} \mathrm{~W} \Omega \mathrm{K}^{-2}$ for TAGS materials with vacancies), ${ }^{2-4} T$ is temperature, and $\sigma$ is the total electrical conductivity, the only way to improve the thermoelectric properties of a material via thermal conductivity modification is to decrease 
the lattice component of this parameter $\left(\kappa_{1}\right)$. This can be achieved by control of the chemical composition or by modifications of the material structure to provide efficient scattering of phonons.

In the development of $\mathrm{TE}$ materials, many semiconducting chalcogenides have attracted much attention. Various materials such as $\mathrm{AgIn}_{x} \mathrm{Sb}_{1-x} \mathrm{Te}_{2},{ }^{5,6} \mathrm{AgSbTe}_{2},{ }^{7} \mathrm{Ge}-\mathrm{Sb}-\mathrm{Te},{ }^{8} \mathrm{Ge}-\mathrm{Pb}-\mathrm{Sn}-$ $\mathrm{Te},{ }^{9,10} \mathrm{AgPb}_{m} \mathrm{Sb}_{n} \mathrm{Te}_{2+m}$ (known as LAST materials $),{ }^{11}$ and $(\mathrm{GeTe})_{x}\left(\mathrm{AgSbTe}_{2}\right)_{100-x}$ with $x=80$ or 85 (known as TAGS materials) reach bulk $Z T$ values of around 1. Thermoelectric properties can be controlled by suitable structural modifications. To reduce the lattice component of the thermal conductivity, modifications such as nanostructuring, thin films, or multilayer systems can be performed. Nanostructuration of LAST materials, which leads to reduction of $\kappa_{\mathrm{l}}$, can increase $Z T$ up to $1.7^{12,13}$ and even 2.1. ${ }^{11}$ TAGS80 and TAGS85 compounds have long been used in radioisotope thermoelectric generators. At $477^{\circ} \mathrm{C}$, a thermoelectric generator operating with optimized TAGS gives $Z T$ values of about 1.5. ${ }^{14}$ In 2014, Schröder et al. ${ }^{2}$ reported that, in TAGS nanostructured through phase transitions associated with vacancy ordering, the $Z T$ value reached 1.6 at $360^{\circ} \mathrm{C}$.

In previous literature reports, many different methods for fabrication of thermoelectric alloys have been reported. The most commonly used are melting of high-purity elements in evacuated quartz ampoules and keeping at about $1000^{\circ} \mathrm{C},,^{3,8,15,16}$ or a mechanical milling process using pure metals as raw materials. ${ }^{17}$ To produce nanostructured materials, a wet precipitation process ${ }^{18}$ and vapor condensation ${ }^{19}$ are often adopted. Lee and $\mathrm{Ha}$ reported ${ }^{20}$ that, through mechanical milling of oxide reagents, calcination, and reduction in hydrogen, they were able to control the thermoelectric properties of the final $\mathrm{Bi}_{0.5} \mathrm{Sb}_{1.5} \mathrm{Te}_{3}$ alloy depending on the duration of the reduction process. Melted oxides in amorphous or polycrystalline form usually exhibit low thermal and electrical conductivity. One of the ways to increase the electrical conductivity of oxide materials is reduction of the metal ions. Kusz and his group examined the formation of both pure metal grains or a composite of metal alloy and amorphous oxide during heat treatment at $340^{\circ} \mathrm{C}$ to $400^{\circ} \mathrm{C}$ in hydrogen atmosphere for various oxide glasses, e.g., Bi-Si-K-O ${ }^{21} \mathrm{Bi}-\mathrm{Ge}-\mathrm{K}-\mathrm{O},{ }^{21} \mathrm{Bi}-\mathrm{Si}-\mathrm{O},{ }^{22,23}$ Bi-Ge-O, ${ }^{24-28} \mathrm{~Pb}-\mathrm{Ge}-\mathrm{O},{ }^{29}$ and Ge-Sb-O. ${ }^{30}$ They have shown that the structure and physical properties of the reduced oxides depend strongly on temperature and the duration of reduction. The reduction process of $\mathrm{Bi}^{3+}$ and $\mathrm{Ge}^{4+}$ ions in hydrogen atmosphere in the temperature range of $320^{\circ} \mathrm{C}$ to $400^{\circ} \mathrm{C}$ leads to the formation of neutral $\mathrm{Bi}^{0}$ and $\mathrm{Ge}^{0}$ atoms. After agglomeration into granules, a uniform metal or semiconductor structure can be formed. These results provided the idea for a new technology for TE materials production. Melting of oxide powders at high temperature in air, quenching, milling once again into powder, and then reducing in hydrogen should lead to the formation of complex structure. Depending on the initial composition of reagents and the temperature and duration of reduction, various products can be obtained. In our previous papers, ${ }^{31,32}$ it was shown that, using this method, it is possible to fabricate bismuth telluride and bismuth antimony telluride alloys with different structures and charge carriers, and good thermoelectric properties.

There are certain oxides and polycrystalline materials which can be fully reduced under heating in hydrogen atmosphere. The rate of this process strongly depends on the energy of the chemical bonds between the cation and oxygen atoms. Dimitrow et al. ${ }^{33}$ reported values for the element binding energies for many pure oxide systems. Low binding energy $\left(E_{\mathrm{b}}<32 \mathrm{eV}\right)$ was noticed for $\mathrm{Bi}, \mathrm{Sb}$, $\mathrm{Te}, \mathrm{Ge}, \mathrm{Ag}, \mathrm{Pb}, \mathrm{Sn}, \mathrm{Na}, \mathrm{In}$, and Co elements. It is important to notice that most thermoelectric materials working at $600^{\circ} \mathrm{C}$ to $700^{\circ} \mathrm{C}$ are prepared with these chemical elements.

In this study, the result of reduction in hydrogen of melted $38.2 \mathrm{GeO}_{2}-51.7 \mathrm{TeO}_{2}-6.72 \mathrm{AgNO}_{3}-3.38 \mathrm{Sb}_{2} \mathrm{O}_{3}$ oxides [denoted as $(\mathrm{GeTe})_{0.85}\left(\mathrm{AgSbTe}_{2}\right)_{0.15}$ or TAGS85] was deeply investigated. As a result of the reduction, the expected $\mathrm{Ge}_{0.73} \mathrm{Ag}_{0.135} \mathrm{Sb}_{0.115} \mathrm{Te}_{1}$ composition was obtained, the same as TAGS85 reported in literature. ${ }^{34}$

\section{EXPERIMENTAL PROCEDURES}

The investigated oxide precursors were produced from appropriate reagent-grade oxides $\left(\mathrm{TeO}_{2}, \mathrm{AgO}\right.$, $\mathrm{GeO}_{2}$, and $\mathrm{Sb}_{2} \mathrm{O}_{3}$ ). First, the reagents were mixed for 30 min using an agate mortar and melted in a ceramic crucible at $1000^{\circ} \mathrm{C}$ in air for $2 \mathrm{~h}$. Next, samples were poured onto cold stainless-steel plate. This process caused quenching of the melt, resulting in bulk samples. In the next step, the samples were milled to small-particle form (around $4 \mu \mathrm{m}$ to $5 \mu \mathrm{m}$ ). Then, the obtained powder was reduced at $280^{\circ} \mathrm{C}$, $300^{\circ} \mathrm{C}, 320^{\circ} \mathrm{C}, 340^{\circ} \mathrm{C}$ or $400^{\circ} \mathrm{C}$ in $\mathrm{H}_{2}$ for $10 \mathrm{~h}$ (denoted as TAGS-R280h10 to TAGS-R400h10). After that, the samples were uniaxially pressed in a cylindrical matrix $(\sim 60 \mathrm{MPa})$ at elevated temperature $\left(340^{\circ} \mathrm{C}\right)$ in argon atmosphere, yielding bulk cylindrical pellets ( $h \approx 5 \mathrm{~mm}$; $\varnothing 5 \mathrm{~mm}$ ) of metallic color.

To investigate the influence of the reducing time, a series of samples was reduced at $400^{\circ} \mathrm{C}$ for $2.5 \mathrm{~h}$, $10 \mathrm{~h}$, and $20 \mathrm{~h}$. Then, after pressing in the same way as for TAGS-R280h10 to TAGS-R400h10, the samples were reduced in hydrogen atmosphere at $400^{\circ} \mathrm{C}$ for the next $2.5 \mathrm{~h}, 10 \mathrm{~h}$, and $20 \mathrm{~h}$ at $400^{\circ} \mathrm{C}$, respectively (denoted as TAGS-R400h $2.5+2.5$, TAGSR400h $10+10$, and TAGS-R400h20 + 20). Only the TAGS-R400h10bis sample was pressed under different conditions $\left(\sim 500 \mathrm{MPa}\right.$ at $180^{\circ} \mathrm{C}$ in hydrogen atmosphere). The compositions of the samples and corresponding abbreviations depending on the 
reduction temperature are listed in Table I, which also presents the density of the samples as measured by the Archimedes method and the calculated porosities.

X-ray diffraction (XRD) analysis was used to determine the phase composition and structure of as-melted and reduced samples, using an X'Pert Pro MPD Philips diffractometer with $\mathrm{Cu} \mathrm{K}_{\alpha}(1.542 \AA)$ radiation at room temperature. The size of crystallites (presented in Table I) was calculated using the Scherrer formula. The morphology of the samples was recorded using an FEI Quanta FEG 250 scanning electron microscope (SEM) with a secondary-electron detector operating in high-vacuum mode at accelerating voltage of $10 \mathrm{kV}$. Maps of element distribution were collected using energydispersive x-ray spectroscopy (EDX) using an EDAX Genesis APEX 2i with an ApolloX SDD spectrometer at accelerating voltage of $20 \mathrm{kV}$.

The electrical conductivity $(\sigma)$ using the fourterminal direct-current (DC) method and Seebeck coefficient $(\alpha)$ of the cylindrical samples were measured over the temperature range from $20^{\circ} \mathrm{C}$ to $340^{\circ} \mathrm{C}$ in argon atmosphere. The values of the Seebeck coefficient were calculated in reference to Pt. The total thermal conductivity was determined at $35^{\circ} \mathrm{C}$ on the basis of analysis of the heat transfer between two copper blocks in vacuum conditions. The electronic part of the thermal conductivity $\left(\kappa_{\mathrm{e}}\right)$ was calculated from the Wiedemann-Franz relationship (Eq. 2). The lattice part of the thermal conductivity $\left(\kappa_{1}\right)$ was determined at $35^{\circ} \mathrm{C}$ as the difference between the measured total $(\kappa)$ and electronic $\left(\kappa_{\mathrm{e}}\right)$ thermal conductivities.

\section{RESULTS AND DISCUSSION}

\section{Structural Properties}

The x-ray diffraction patterns of the as-prepared TAGS85 sample and those reduced at different temperatures of $280^{\circ} \mathrm{C}, 300^{\circ} \mathrm{C}, 320^{\circ} \mathrm{C}, 340^{\circ} \mathrm{C}$, and $400^{\circ} \mathrm{C}$ in $\mathrm{H}_{2}$ for $10 \mathrm{~h}$ are presented in Fig. 1. The halo pattern of the as-prepared sample is characteristic of amorphous or highly disordered structures, with one wide peak (at $2 \theta \approx 28^{\circ}$ ) showing that the obtained material could be partially crystallized. For the sample reduced at $280^{\circ} \mathrm{C}$, some crystalline peaks can be observed, but the very low intensity does not allow unambiguous identification of the phases formed. Starting from the reduction temperature of $300^{\circ} \mathrm{C}$, rhombohedral GeTe structure in space group $R 3 m$ (reference pattern PDF 01072-1835) characteristic of TAGS materials can be observed. The peak broadening and calculations using Scherrer's equation indicated that the nanostructured crystalline phase was obtained. Moreover, no additional phases could be identified in the analyzed XRD plots. In contrast to the other samples, the TAGS-R400h10bis sample exhibited a rocksalt-type cubic structure. According to previous literature reports of Yang et al., ${ }^{3}$ it can be concluded that the different fabrication method for TAGS$\mathrm{R} 400 \mathrm{~h} 10$ bis could decrease the $\mathrm{Ag} / \mathrm{Sb}$ ratio, resulting in the formation of a sample with cubic structure.

To investigate the influence of the reduction time on the structural and electrical properties of the TAGS samples, different processing times at constant temperature of $400^{\circ} \mathrm{C}$ were applied. A comparison between the XRD patterns of the samples reduced in $\mathrm{H}_{2}$ for $2.5 \mathrm{~h}+2.5 \mathrm{~h}, 10 \mathrm{~h}+10 \mathrm{~h}$, and $20 \mathrm{~h}+20 \mathrm{~h}$ is shown in Fig. 2. In the plot for the TAGS-R400h2.5 + 2.5 sample, the presence of GeTe nanogranular cubic structure in space group $R 3 m$ is noticed. Moreover, some peaks which can be attributed to $\mathrm{Ge}_{2} \mathrm{Sb}_{2} \mathrm{Te}_{5}$ hexagonal phase in space group $P-3 m 1$ were found. In samples reduced at $400^{\circ} \mathrm{C}$ for $10 \mathrm{~h}+10 \mathrm{~h}$ or $20 \mathrm{~h}+20 \mathrm{~h}$, only the presence of GeTe rhombohedral $R 3 \mathrm{~m}$ phase was noticed. The narrower peak width related to

Table I. Sample composition, reduction conditions, corresponding abbreviation, and measured density, porosity, and total thermal conductivity

\begin{tabular}{|c|c|c|c|c|c|}
\hline Abbreviation & $\begin{array}{c}\text { Reduction Temperature } \\
\left({ }^{\circ} \mathbf{C}\right) / \text { Time }(h)\end{array}$ & $\begin{array}{l}\text { Density } \\
\left(\text { g cm }^{-3}\right)\end{array}$ & $\begin{array}{l}\text { Porosity } \\
(\%)\end{array}$ & $\begin{array}{l}\text { Crystallite } \\
\text { Size (nm) }\end{array}$ & $\begin{array}{l}\text { Total Thermal } \\
\text { Conductivity } \\
\left(\mathbf{W} \mathbf{m}^{-1} \mathbf{K}^{-1} \text { ) }\right.\end{array}$ \\
\hline TAGS-O & - & 6.25 & 3 & - & - \\
\hline TAGS-R280h10 & $280 / 10$ & 3.70 & 14 & - & 0.61 \\
\hline TAGS-R300h10 & $300 / 10$ & 3.98 & 28 & 27 & 0.88 \\
\hline TAGS-R320h10 & $320 / 10$ & 4.35 & 10 & 22 & 1.30 \\
\hline TAGS-R340h10 & $340 / 10$ & 4.50 & 8 & 37 & 1.10 \\
\hline TAGS-R400h10 & $400 / 10$ & 4.87 & 23 & $>300$ & 0.93 \\
\hline TAGS-R400h10bis & $400 / 10$ & 5.09 & 17 & $>300$ & - \\
\hline TAGS-R400h $2.5+2.5$ & $400 / 2.5+2.5$ & 4.85 & 5 & 101 & 0.91 \\
\hline TAGS-R400h $10+10$ & $400 / 10+10$ & 4.70 & 18 & $>300$ & 0.90 \\
\hline TAGS-R400h20 + 20 & $400 / 20+20$ & 4.76 & 12 & $>300$ & 0.85 \\
\hline
\end{tabular}

Accuracy: $\pm 5 \%$. 


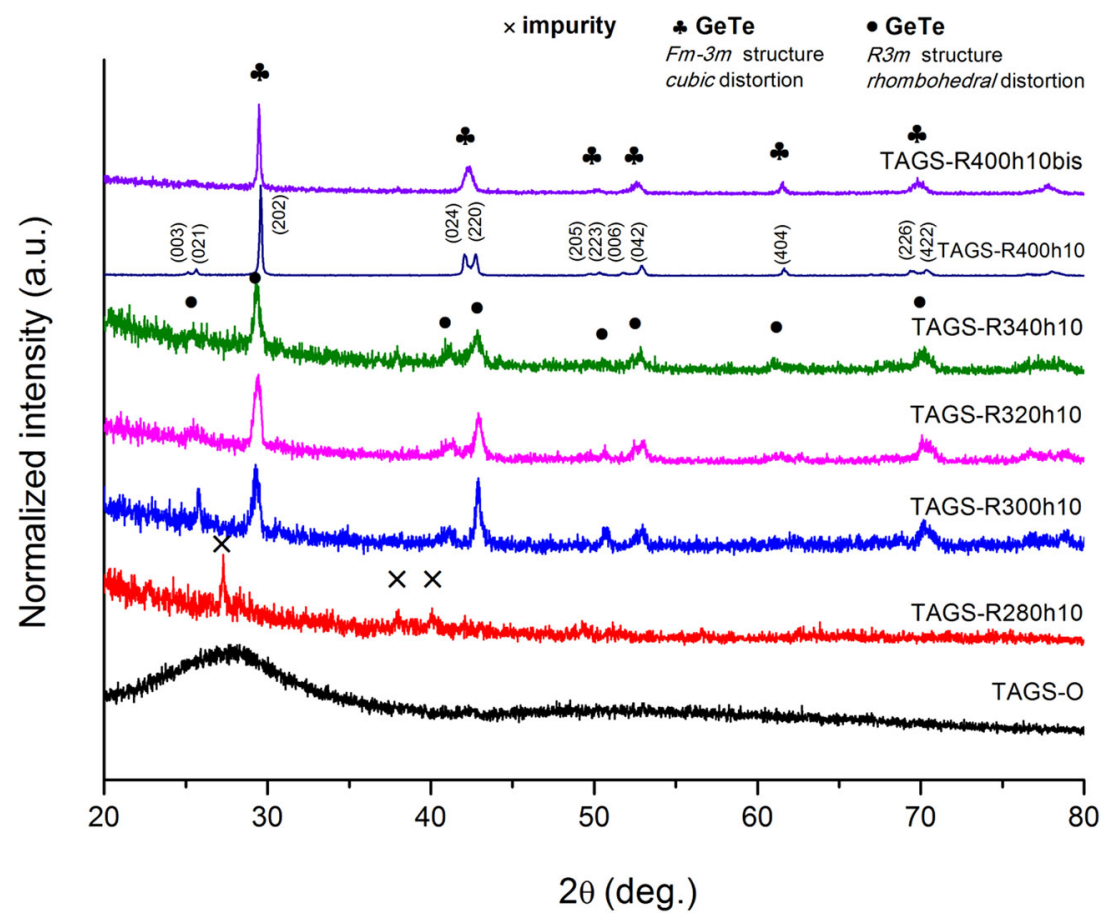

Fig. 1. XRD patterns of TAGS samples before and after reduction at different temperatures.

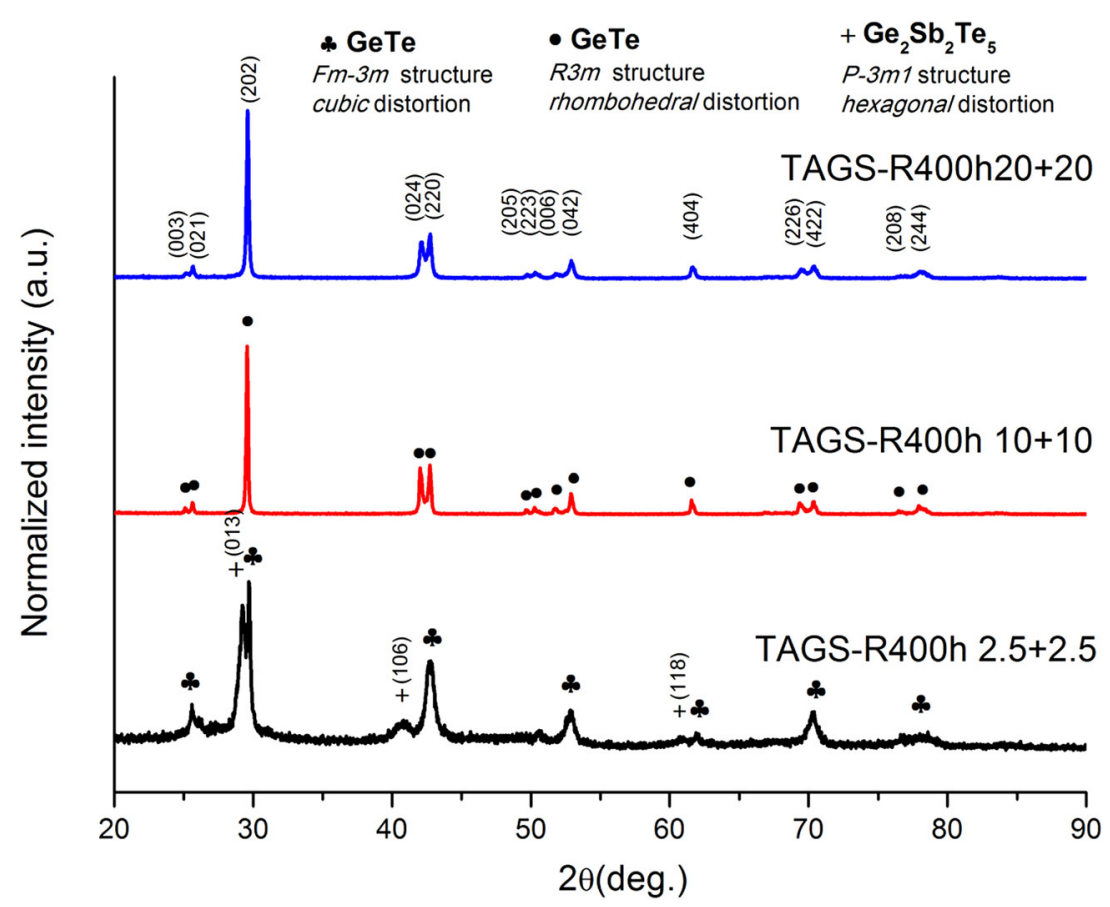

Fig. 2. XRD patterns of TAGS samples after reduction at $400^{\circ} \mathrm{C}$ for different times $(2.5 \mathrm{~h}+2.5 \mathrm{~h}, 10 \mathrm{~h}+10 \mathrm{~h}$, and $20 \mathrm{~h}+20 \mathrm{~h})$.

increased crystallite size allowed the observation of the (024) and (220) double peak characteristic of the rhombohedral phase.

The values of density, porosity, and crystallite size for the TAGS samples reduced at different temperatures and for different durations are presented in Table I. Schröder et al. ${ }^{2}$ reported a theoretical density value for a TAGS sample of similar composition (based on XRD results) of $\rho=6.4 \mathrm{~g} \mathrm{~cm}^{-3}$. As seen in Table I, samples reduced at $400^{\circ} \mathrm{C}$ for $10 \mathrm{~h}$ exhibited a density lower than the theoretical value (about 24\%). The porosity of the 
composition was obtained in the range of $5 \%$ to $23 \%$. The average crystallite sizes were estimated using Scherrer's equation. The results for the samples reduced at $300^{\circ} \mathrm{C}, 320^{\circ} \mathrm{C}$, and $340^{\circ} \mathrm{C}$ were $27 \mathrm{~nm}$, $22 \mathrm{~nm}$, and $37 \mathrm{~nm}$, respectively. In the case of all compositions reduced at $400^{\circ} \mathrm{C}$, the crystallite size was greater than $300 \mathrm{~nm}$, except for the TAGSR400h2.5 + 2.5 sample, where the size was estimated as $100 \mathrm{~nm}$.

The morphology and composition of the samples after reduction in hydrogen were analyzed using SEM and EDX techniques. EDX analysis of the element distribution was performed at six different characteristic points of the sample. The SEM image of a polished cross-section of the TAGS-R400h10 sample is shown in Fig. 3, marked with EDX spots. Spots 1, 2, and 3 are situated inside large grains, whereas spots 4,5 , and 6 are generally situated in pores and grain boundaries. The quantitative results obtained by EDX analysis are presented in Table II as the atomic percentage (at.\%) of each element.

The obtained results confirm that the composition inside the grains of the TAGS-R400h10 + 10 sample is close to the nominal $\mathrm{Ge}_{0.73} \mathrm{Ag}_{0.135} \mathrm{Sb}_{0.115} \mathrm{Te}_{1}$ composition. Moreover, the EDX results at spots 4, 5, and 6 show that, in grain boundaries and pores, the elements $\mathrm{Ge}, \mathrm{Ag}, \mathrm{Sb}, \mathrm{Te}$, and $\mathrm{O}$ are present, as well as a trace amount of $\mathrm{Al}\left(\mathrm{Al}_{2} \mathrm{O}_{3}\right.$, probably from the ceramic crucible used during the fabrication process). Grains of the sample reduced for $2.5 \mathrm{~h}+2.5 \mathrm{~h}$ are visibly depleted of silver, whereas slight tellurium depletion could be observed in grain boundaries and pores of this sample.

\section{Influence of Reduction Temperature on TE Properties}

To determine the usability of the TAGS material in thermoelectric applications, the total electrical conductivity, Seebeck coefficient, and thermal conductivity were measured, and the $Z T$ parameter was estimated on the basis of the obtained experimental results. ${ }^{2}$

In Fig. 4 the dependence of the electrical conductivity $(\sigma)$ for the TAGS85 samples reduced in the temperature range from $280^{\circ} \mathrm{C}$ to $400^{\circ} \mathrm{C}$ for $10 \mathrm{~h}$ is presented.

The lowest total electrical conductivity was measured for the TAGS-R280h10 specimen, being around two orders of magnitude lower than for other samples. For most of the investigated compositions, except TAGS-R400h10, the changes of the electrical conductivity in the applied temperature range of $20^{\circ} \mathrm{C}$ to $340^{\circ} \mathrm{C}$ are quite small. However, a small deviation from linearity is observed in Fig. 4 at $\sim 200^{\circ} \mathrm{C}$. This behavior is probably caused by the phase transition. ${ }^{35}$

The temperature dependence of the Seebeck coefficient $(\alpha)$ for TAGS samples reduced at various temperatures from $280^{\circ} \mathrm{C}$ to $400^{\circ} \mathrm{C}$ for $10 \mathrm{~h}$ is shown in Fig. 5.

As shown by the results in Fig. 5, the highest Seebeck coefficient $\left(265 \mu \mathrm{V} \mathrm{K}^{-1}\right.$ at $\left.200^{\circ} \mathrm{C}\right)$ was obtained for the TAGS-R400h10 sample. The same value was observed for TAGS-R280h10, but this sample exhibited the lowest electrical conductivity of all the measured compositions. The Seebeck coefficient of other samples was comparable at $340^{\circ} \mathrm{C}$, being around $100 \mu \mathrm{V} \mathrm{K}^{-1}$.

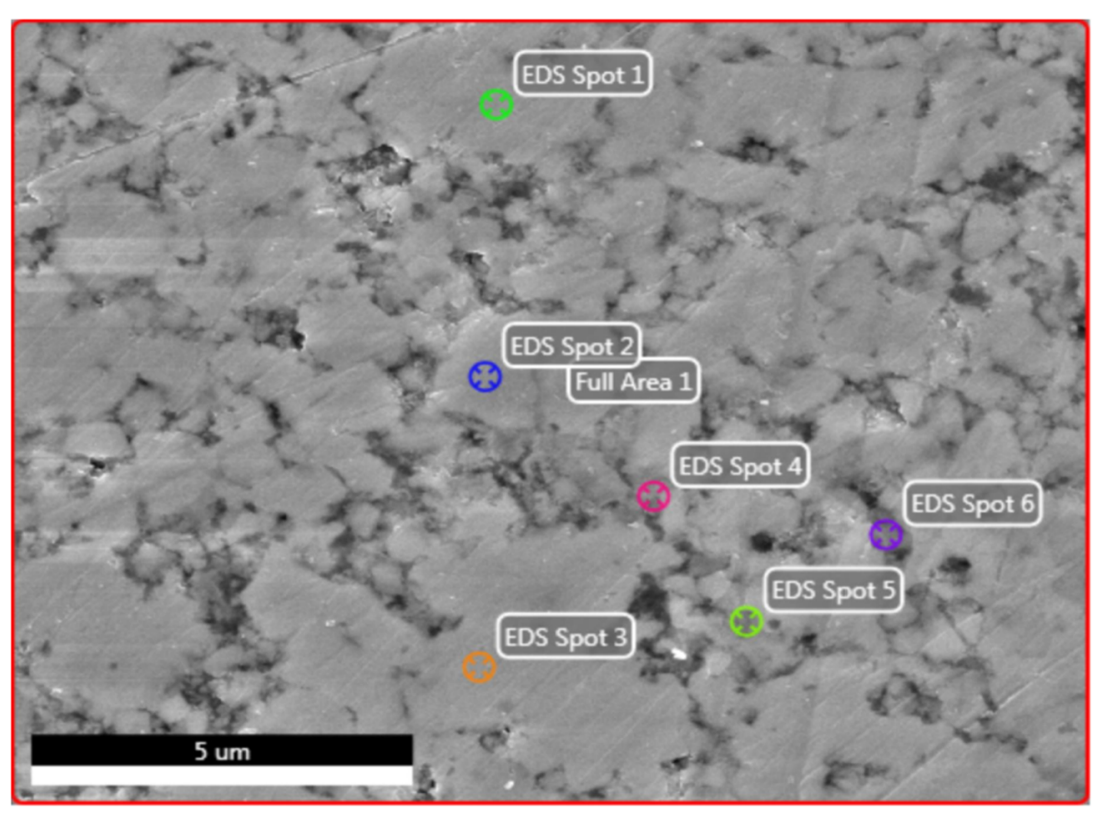

Fig. 3. SEM image of polished cross-section of TAGS-R400h10 + 10 sample with EDX spots marked. 
Table II. Results of EDX analysis performed on polished cross-section of samples after reduction at $400^{\circ} \mathrm{C}$ for $2.5 \mathrm{~h}+2.5 \mathrm{~h}, 10 \mathrm{~h}+10 \mathrm{~h}$, and $20 \mathrm{~h}+20 \mathrm{~h}$

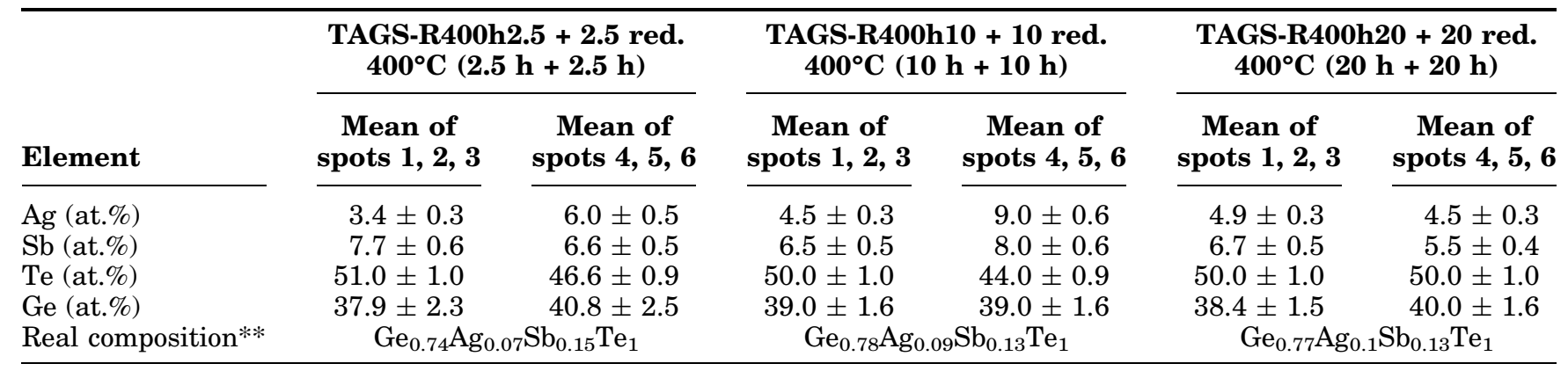

Values calculated as averages of a group of spots inside $(1,2,3)$ or outside $(4,5,6)$ the grain. The uncertainties for each element are also shown. Trace amount of oxygen and $\mathrm{Al}_{2} \mathrm{O}_{3}$ at spots 4, 5, 6 was not taken into account.**Real composition calculated from data of spots $1,2,3$.

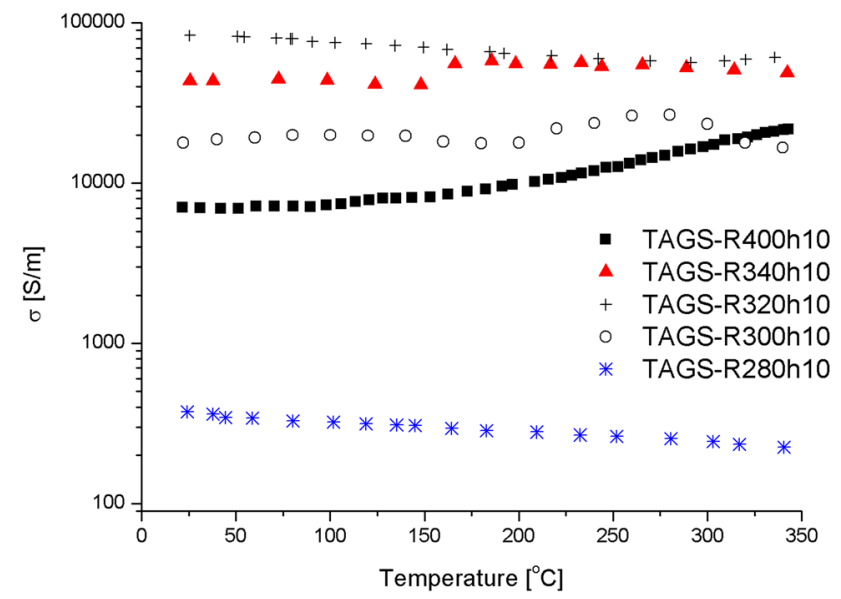

Fig. 4. Temperature dependence of electrical conductivity $(\sigma)$ for TAGS85 reduced at various temperatures from $280^{\circ} \mathrm{C}$ to $400^{\circ} \mathrm{C}$ for $10 \mathrm{~h}$.

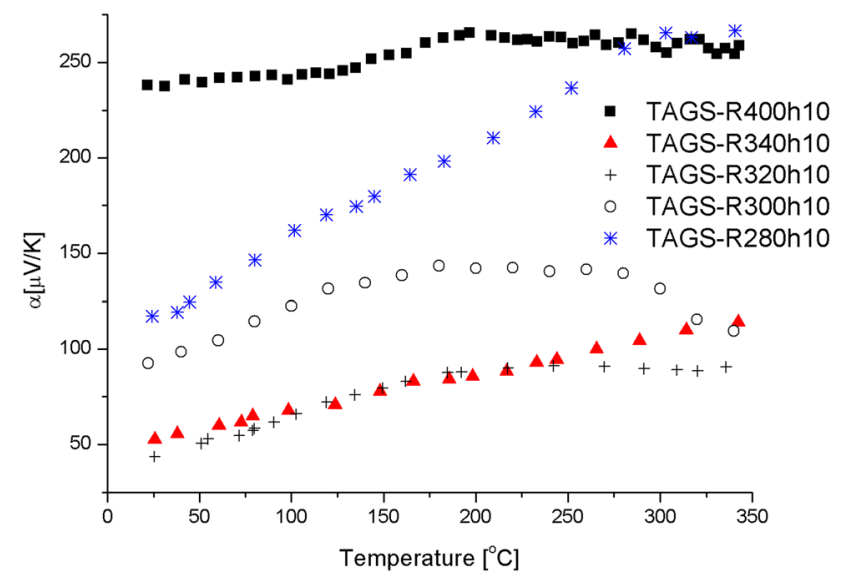

Fig. 5. Temperature dependence of Seebeck coefficient $(\alpha)$ for TAGS85 samples reduced at various temperatures from $280^{\circ} \mathrm{C}$ to $400^{\circ} \mathrm{C}$ for $10 \mathrm{~h}$.

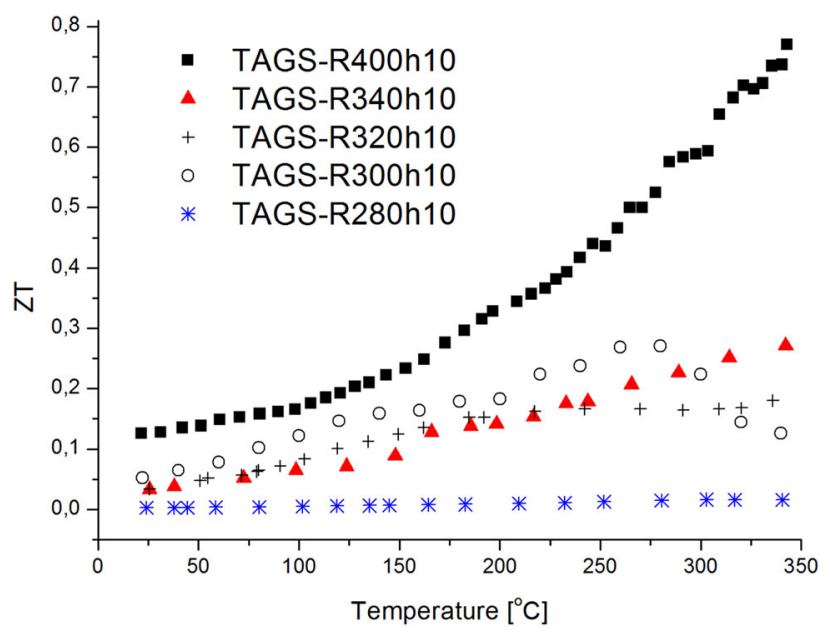

Fig. 6. Temperature dependence of figure of merit $(Z T)$ for TAGS85 reduced at various temperatures from $280^{\circ} \mathrm{C}$ to $400^{\circ} \mathrm{C}$ for $10 \mathrm{~h}$.

The temperature dependence of the estimated figure of merit $(Z T)$ for TAGS85 reduced at various temperatures from $280^{\circ} \mathrm{C}$ to $400^{\circ} \mathrm{C}$ for $10 \mathrm{~h}$ is presented in Fig. 6.

The $Z T$ values were estimated according to Eq. 1 . The electronic part of the thermal conductivity $\left(\kappa_{\mathrm{e}}\right)$ was calculated from the Wiedemann-Franz relationship (Eq. 2). The lattice part of the thermal conductivity $\left(\kappa_{1}\right)$ was determined at $35^{\circ} \mathrm{C}$ as the difference between the measured total $(\kappa)$ and electronic $\left(\kappa_{\mathrm{e}}\right)$ thermal conductivities; To estimate $Z T$ it was assumed to be constant over the whole temperature range. The measured values of total thermal conductivity at $35^{\circ} \mathrm{C}$ are presented in Table I. The temperature dependence of the obtained figure of merit $(Z T)$ for TAGS85 is presented in Fig. 6. The plots indicate that the highest $Z T$ parameter was obtained for TAGS-R400h10 $\left(Z T=0.7\right.$ at $\left.340^{\circ} \mathrm{C}\right)$. It should also be noticed that the $Z T$ value increased with temperature for almost 
all the investigated samples and did not reach a maximum in the analyzed temperature range. Only for TAGS-R300h10 was a maximum value of $Z T=0.2$ found.

\section{Influence of Reduction Time on TE Properties}

The influence of the reduction time on the structural and electrical properties of the fabricated TAGS material was also investigated.

The temperature dependence of the electrical conductivity $(\sigma)$ for the TAGS85 samples reduced at $400^{\circ} \mathrm{C}$ for $2.5 \mathrm{~h}+2.5 \mathrm{~h}, 10 \mathrm{~h}+10 \mathrm{~h}$, and $20 \mathrm{~h}+20 \mathrm{~h}$, respectively, is shown in Fig. 7 .

It is clear that the lowest total electrical conductivity was obtained for the TAGS-R400h20 + 20 sample $\left(21 \times 10^{3} \mathrm{~S} \mathrm{~m}^{-1}\right.$ at $\left.340^{\circ} \mathrm{C}\right)$, whereas the highest value was observed for TAGS-R400h10 + 10 $\left(42 \times 10^{3} \mathrm{~S} \mathrm{~m}^{-1}\right)$. Moreover, some anomalies in the $\sigma(T)$ relation can be observed at $200^{\circ} \mathrm{C}$. This behavior is probably caused by the phase transition. ${ }^{35}$ The temperature dependence of the Seebeck coefficient $(\alpha)$ for $38 \mathrm{GeO}_{2}-52 \mathrm{TeO}_{2}-7 \mathrm{AgNO}_{3}-3 \mathrm{Sb}_{2} \mathrm{O}_{3}$ samples reduced at $400^{\circ} \mathrm{C}$ for $2.5 \mathrm{~h}+2.5 \mathrm{~h}, 10 \mathrm{~h}+10 \mathrm{~h}$, and $20 \mathrm{~h}+20 \mathrm{~h}$ is presented in Fig. 8. For all the investigated samples, the Seebeck coefficient increased with temperature. The highest value $\left(255 \mu \mathrm{V} \mathrm{K}^{-1}\right.$ at $\left.340^{\circ} \mathrm{C}\right)$ was reached for the TAGSR400h20 + 20 sample. According to the obtained results, it can be concluded that the $\alpha$ value increases with increasing reduction time.

The temperature dependence of the estimated $Z T$ is presented in Fig. 9. Similar to Fig. 6, the $Z T$ values were estimated under the assumption that the lattice thermal conductivity is constant over the whole temperature range. A particular value of $\kappa_{1}$ was determined at $35^{\circ} \mathrm{C}$ as the difference between the measured total $(\kappa)$ and electronic $\left(\kappa_{\mathrm{e}}\right)$ thermal conductivities. The measured values of

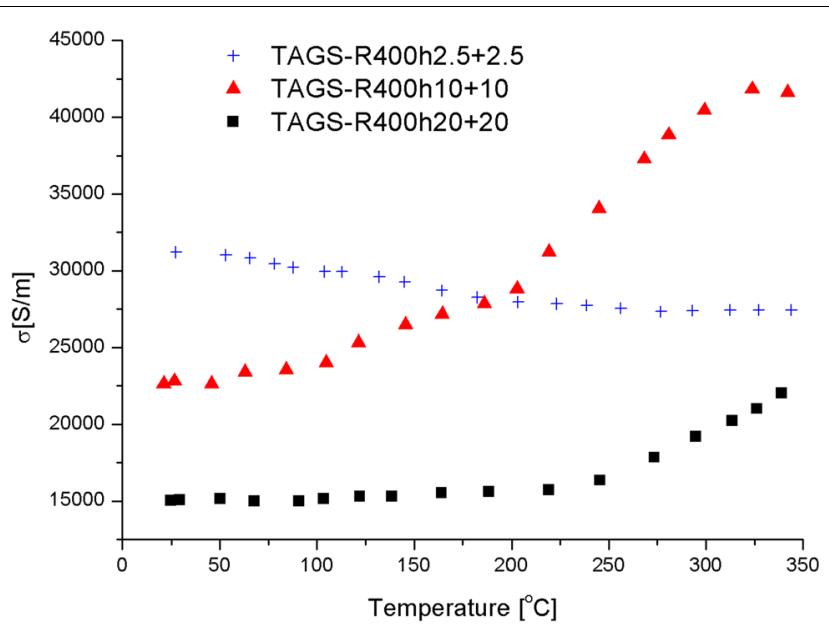

Fig. 7. Temperature dependence of electrical conductivity $(\sigma)$ for TAGS85 reduced at $400^{\circ} \mathrm{C}$ for $2.5 \mathrm{~h}+2.5 \mathrm{~h}, 10 \mathrm{~h}+10 \mathrm{~h}$, and $20 \mathrm{~h}+20 \mathrm{~h}$. total thermal conductivity at $35^{\circ} \mathrm{C}$ are presented in Table I. The lowest $Z T$ value was obtained for TAGS-R400h2.5 $+2.5\left(0.16\right.$ at $\left.340^{\circ} \mathrm{C}\right)$, whereas the highest value $\left(0.93\right.$ at $\left.340^{\circ} \mathrm{C}\right)$ was observed for TAGS-R400h $10+10$ and TAGS-R400h $20+20$. It is interesting that the $Z T$ parameter of samples with the same structure (TAGS-R400h10 + 10 and TAGS-R400h20 + 20) seems to be independent of the reduction time. Moreover, as mentioned above, some authors have proved that the total thermal conductivity of TAGS sample is almost independent of temperature. ${ }^{2,3,33,35}$ We found that, if the total thermal conductivity is also constant for our samples (e.g., the increase of $\kappa_{\mathrm{e}}$ is compensated by a decrease of $\kappa_{1}$ ), then the estimated value of $Z T$ of TAGS-R400h10 + 10 could have been higher than 1 at $340^{\circ} \mathrm{C}$.

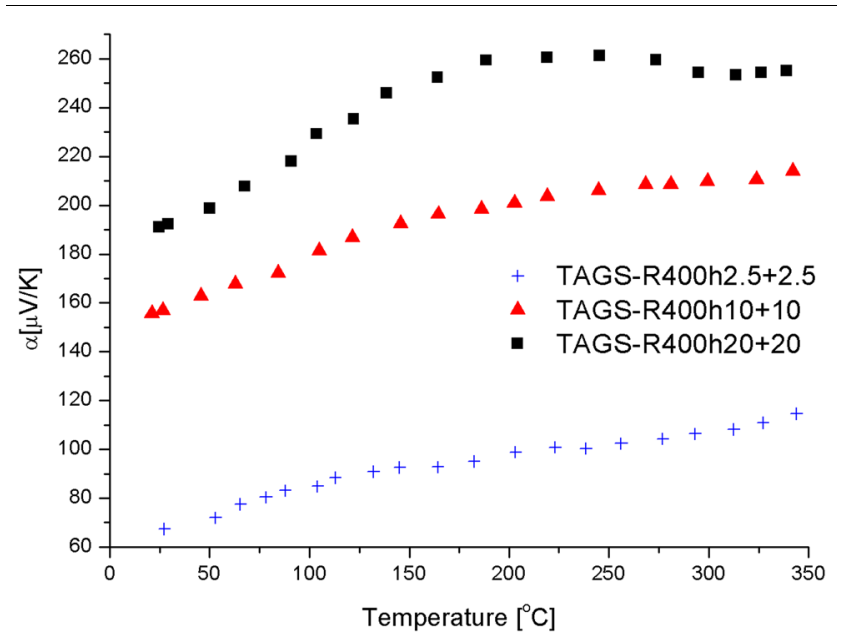

Fig. 8. Temperature dependence of Seebeck coefficient $(\alpha)$ for TAGS85 reduced at $400^{\circ} \mathrm{C}$ for $2.5 \mathrm{~h}+2.5 \mathrm{~h}, 10 \mathrm{~h}+10 \mathrm{~h}$, and $20 \mathrm{~h}+20 \mathrm{~h}$.

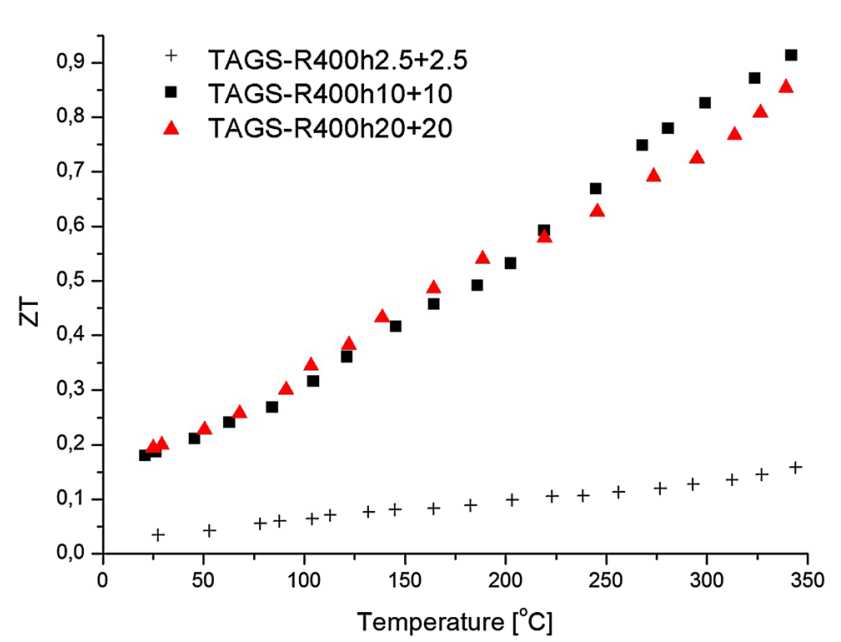

Fig. 9. Temperature dependence of figure of merit $(Z T)$ for TAGS 85 reduced at $400^{\circ} \mathrm{C}$ for $2.5 \mathrm{~h}+2.5 \mathrm{~h}, 10 \mathrm{~h}+10 \mathrm{~h}$, and $20 \mathrm{~h}+20 \mathrm{~h}$. 


\section{CONCLUSIONS}

A novel fabrication method for TAGS thermoelectric materials is presented. The oxide mixture $38.2 \mathrm{GeO}_{2}-51.7 \mathrm{TeO}_{2}-6.72 \mathrm{AgNO}_{3}-3.38 \mathrm{Sb}_{2} \mathrm{O}_{3}$ was melted at high temperature, quenched to form pellets, milled, and then reduced in hydrogen using various temperatures and times. The $\mathrm{Ge}_{0.77} \mathrm{Ag}_{0.1} \mathrm{Sb}_{0.13} \mathrm{Te}_{1}$ material could be successfully sintered in both crystallographic forms of germanium telluride (GeTe), viz. rhombohedral $R 3 m$ and cubic $F m-3 m$. It was found that the single-phase GeTe nanogranular form could be fabricated above reduction temperature of $280^{\circ} \mathrm{C}$. It is worth underlining that the size of the nanocrystallites increased with the reduction temperature. Furthermore, the duration of the reduction process had a great influence on the final structure and properties of the material. At lower temperatures, TAGS with nanometer-size grains could be fabricated. It was also shown that the size of the crystallites as well as electrical parameters such as the electrical conductivity, Seebeck coefficient, and $Z T$ increased with the reduction duration. Our investigations also showed that this fabrication method based on reduction of oxides results in very promising materials for thermoelectric applications. The $Z T$ value of $\mathrm{Ge}_{0.77} \mathrm{Ag}_{0.1} \mathrm{Sb}_{0.13} \mathrm{Te}_{1}$ (samples TAGS$\mathrm{R} 400 \mathrm{~h} 10+10$ and TAGS-R400h $20+20$ ), under the assumption that the total thermal conductivity is independent of temperature ( $\kappa=$ const.), reached a value of 1.3 and 1.0 , respectively, at $340^{\circ} \mathrm{C}$.

We strongly believe that a well-designed fabrication technique is necessary to obtain a single-phase GeTe structure with promising thermoelectric properties. Based on our experience, we conclude that the use of pure substrates, melting in a platinum crucible, ball-milling, and reduction under optimal conditions will allow bulk TAGS samples with high potential for application in $\mathrm{TE}$ devices to be obtained. Thus, a wide group of $\mathrm{TE}$ materials working at less than $700^{\circ} \mathrm{C}$ can be prepared using our novel method. In addition, by varying the composition, and temperature and duration of reduction, it may be possible to obtain nanostructured $\mathrm{TE}$ material with one of the highest $Z T$ values.

\section{ACKNOWLEDGEMENTS}

The authors would like to acknowledge Witold Lizak for help with sample fabrication and Prof. Maria Gazda for support with XRD measurements. This work was funded by the National Science Center under Grant No. NCN 2012/05/B/ST3/02816.

\section{OPEN ACCESS}

This article is distributed under the terms of the Creative Commons Attribution 4.0 International License (http://creativecommons.org/licenses/by/4.0/), which permits unrestricted use, distribution, and reproduction in any medium, provided you give appropriate credit to the original author(s) and the source, provide a link to the Creative Commons license, and indicate if changes were made.

\section{REFERENCES}

1. G.A. Slack, CRC Handbook of Thermoelectrics (Boca Raton: CRC Press, 1995), p. 407.

2. T. Schröder, T. Rosenthal, N. Giesbrecht, M. Nentwig, and S. Maier, Inorg. Chem. 53, 7722 (2014).

3. S.H. Yang, T.J. Zhu, S.N. Zhang, J.J. Shen, and X.B. Zhao, J. Electron. Mater. 39, 2127 (2010).

4. T. Zhu, H. Gao, Y. Chen, and X.B. Zhao, J. Mater. Chem. A 2, 3251 (2014).

5. R. Mohanraman, R. Sankar, K.M. Boopathi, F.C. Chou, C.W. Chu, C.H. Lee, and Y.Y. Chen, J. Mater. Chem. A 2, 2839 (2014).

6. T. Schröder, T. Rosenthal, D. Souchay, C. Petermayer, S. Grott, E.W. Scheidt, C. Gold, W. Scherer, and O.J. Oeckler, J. Solid State Chem. 206, 20 (2013).

7. D.T. Morelli, V. Jovovic, and J.P. Heremans, Phys. Rev. Lett. 101, 035901 (2008).

8. F. Yan, T.J. Zhu, X.B. Zhao, and S.R. Dong, Appl. Phys. A 88, 425 (2007).

9. Y. Gelbstein, Y. Rosenberg, Y. Sadia, and M.P. Dariel, J. Phys. Chem. C 114, 13126 (2010).

10. D. Wu, L.D. Zhao, Q.H. Wu, H. Chi, Y. Gelbstein, C. Uher C. Wolverton, M.I. Kanatzidis, and L. He, J. Am. Chem. Soc. 136, 11412 (2014).

11. K.F. Hsu, S. Loo, F. Guo, W. Chen, J.S. Dyck, C. Uher, T. Hogan, E.K. Polychroniadis, and M.G. Kanatzidis, Science 303, 818 (2004).

12. K.F. Cai, C. Yan, Z.M. He, J.L. Cui, C. Stiewe, and E. Müller, J. Alloy. Compd. 469, 499 (2009).

13. N. Chen, F. Gascoin, G.J. Snyder, E. Muller, G. Karpinski, and C. Stiewe, Appl. Phys. Lett. 87, 171903 (2005).

14. E. Skrabek and D. Trimmer, U.S. patent specification 3945 855 (1976).

15. W. Xie, X. Tang, Y. Yan, Q. Zhang, and T.M. Tritt, Appl. Phys. Lett. 94, 102111 (2009).

16. S. Zhang, G. Jiang, T. Zhu, X. Zhao, and S. Yang, Int. J. Min. Met. Mater. 18, 352 (2011).

17. B. Poudel, Q. Hao, Y. Ma, Y. Lan, A. Minnich, B. Yu, X. Yan, D. Wang, A. Muto, D. Vashaee, X. Chen, J. Liu, M.S Dresselhaus, G. Chen, and Z. Ren, Science 320, 634 (2008). doi:10.1126/science.1156446.

18. J.J. Ritter and P. Maruthamuthu, Inorg. Chem. 34, 4278 (1995).

19. G.G. Lee, D.Y. Lee, and G.H. Ha, Met. Mater. Int. 17, 245 (2011).

20. G. Lee and G.H. Ha, J. Electron. Mater. 43, 1697 (2014).

21. J. Gackowska, M. Gazda, K. Trzebiatowski, and B. Kusz, J. Non Cryst. Solids 354, 4319 (2008). doi:10.1016/j.jnoncrysol. 2008.06.043.

22. B. Kusz, K. Trzebiatowski, and R.J. Barczynski, Solid State Ion. 159, 293 (2003). doi:10.1016/S0167-2738(02)00911-6.

23. A. Witkowska, J. Rybicki, and A. Di Cicco, J. Alloy. Compd. 401, 135 (2005). doi:10.1016/j.jallcom.2005.01.104.

24. B. Kusz and K. Trzebiatowski, J. Non Cryst. Solids 319, 257 (2003). doi:10.1016/S0022-3093(02)01969-5.

25. B. Kusz, K. Trzebiatowski, M. Gazda, and L. Murawski, J. Non Cryst. Solids 328, 137 (2003). doi:10.1016/ S0022-3093(03)00466-6.

26. B. Kusz, J. Non Cryst. Solids 356, 278 (2010). doi: 10.1016/j.jnoncrysol.2003.12.048.

27. B. Kusz, Solid State Commun. 125, 623 (2003). doi: 10.1016/S0038-1098(03)00008-5.

28. B. Bochentyn, J. Karczewski, M. Gazda, and B. Kusz, Procedia Eng. 98, 46 (2014).

29. J. Gackowska, M. Gazda, K. Trzebiatowski, and B. Kusz, J. Non Cryst. Solids 352, 4242 (2006). doi:10.1016/ j.jnoncrysol.2006.07.016.

30. B. Bochentyn, J. Karczewski, M. Gazda, and B. Kusz, Procedia Eng. 98, 51 (2014). 
31. B. Bochentyn, J. Karczewski, T. Miruszewski, and B. Kusz, J. Alloy. Compd. 646, 1124 (2015).

32. B. Bochentyn, J. Karczewski, T. Miruszewski, and B. Kusz, Mater. Res. Bull. (2015).

33. J.Dawidow and T. Komatsu, J. Solid State Chem. 163, 100 (2002).
34. E.A. Skrabek and D.S. Trimmer, CRC Handbook of Thermoelectrics, ed. D.M. Rove (Boca Raton: CRC Press, 1994), p. 267.

35. J. Davidow, Y. Gelbstein, and A. Comparison, J. Electron. Mater. 42, 1542 (2013). 